\title{
Editorial
}

\section{Twenty-first century branding}

As the end of the twentieth century approaches, it is instructive to take stock of what we have learned about brands and brand equity and speculate as to how branding will change in the next century. What will make a successful 'Twenty-first century brand'? As a point of departure, to answer that question, it is worthwhile first considering what are some of the established branding principles that correctly distinguish top marketers and brands. Although a number of different criteria are possible, as to what makes a strong brand, the following list highlights some of the key considerations in effectively building, measuring, and managing brand equity.

To create a strong brand, marketers must:

- Understand what brands mean to consumers and develop products that are appropriate to the brand and address the needs of the target market.

- Properly position brands by achieving necessary and desired points-of-parity and points-of-difference.

- Provide superior delivery of desired benefits all through the marketing programme.

- Maintain innovation in design, manufacturing, and marketing and relevance in brand personality and imagery.

- Establish credibility and be seen as expert, trustworthy, and likeable.

- Communicate with a consistent voice at any one point in time and over time.

- Employ a full range of complementary brand elements and supporting marketing activities.

- Design and implement a brand hierarchy and brand portfolio that puts brands in the proper context with respect to other brands and other products sold by the firm.

Although these general criteria are likely to continue to apply in the coming years, additional, new considerations are also likely to emerge. In the remaining sections, we briefly consider how the role of brands and strategies to build, measure, and manage brand equity may change in the future. 1

\section{ROLE OF BRANDS}

In a general sense, the importance of branding seems unlikely to change for one very important reason: it seems highly likely that consumers will continue to value the multitude of functions provided by brands. That is, in a seemingly more and more complex world, well-managed brands can simplify, communicate, re-assure, and provide important meaning to consumers. The value that consumers place on such abilities for brands seems unlikely to dissipate.

\section{BUILDING BRAND EQUITY}

The basic principles of choosing brand elements, for example, brand names, logos, symbols, characters, slogans, etc, to build brand equity should continue to hold in the coming years. In other words, creating strong brands will still involve combining brand elements in a consistent and complimentary fashion so that, collectively, the brand is memorable, meaningful, transferable, and protectable. That is, smart marketers will employ the full repertoire of brand elements 
to choose vivid brand names that suggest some concrete or abstract benefit, visually reinforced by a logo, symbol, or character and verbally reinforced by a slogan or jingle that enhances awareness and image.

In a cluttered, competitive marketplace with distracted or disinterested consumers, however, those brand elements that make up the brand will have to do more and more of the 'selling job'. In a time-compressed marketing world, the fact that a brand name can be noticed and its meaning registered or activated in memory within just a few seconds is a tremendous asset. Creating a powerful brand with inherent marketing value to build awareness and image, as well as serve as a strong foundation to link associations, can provide a firm with a strong competitive advantage.

Although the general branding principles will apply in designing a twenty-first century brand, what may change, however, are some of the means to create strong brands. The brand elements that are chosen will increasingly involve verbal and visual elements that creatively and dramatically help to build brand equity. Meaningful brands with creative potential will benefit from multiple sensory presentations. Brands have long used auditory branding devices, for example, the three-note Nabisco jingle, the percolating Maxwell House jingle, and the NBC jingle. Movie studios have always been able to take advantage of their cinematic exposure to use sight, sound, and motion to present their brands (eg, Universal's spinning globe, Paramount's mountain peak, and MGM's roaring lion). With increased technical abilities and improved special effects, marketers will now be able to create brand elements that come to life and capture consumer attention, an important quality given the need to communicate and sell through brands in current markets. Thus, the static images of brands with which marketers are used to dealing will be supplemented by multi-dimensional forms that play a more important role in audio and video presentations of the brand.

For example, perhaps one of the strongest brands to emerge in the last decade has been Intel and their Intel Inside microprocessor brand. There are a number of success factors for the brand, but one extremely worthwhile decision they made in their introductory television campaign was to end their advertisements with a picture of the 'Intel Inside' logo dramatically flashing and swirling on the television screen - almost literally 'Intel in your face' — while the voice-over announced: 'The computer inside'. This branding device captured consumers' attention at a critical moment in the advertisement, helping to both build awareness of the Intel brand and linking it to the communication effects engendered by the advertisement - a major challenge in today's difficult media environment.

Thus, a twenty-first century brand will consider how to take advantage of different media to customise the brand presentation so that each brand element more effectively contributes to brand equity through enhanced awareness and image and brand elements more effectively reinforce each other so that they become more consistent and cohesive as a result. Finally, as with the Intel example, smart marketers in the twenty-first century will attempt to find ways to make sure that strong brand associations are created to all possible marketing effects. In particular, it will be necessary to consider carefully and imaginatively how the brand itself will be effectively integrated into the marketing programme to maximise its contribution to brand equity. In other words, the issue will not just be which brand elements are chosen to represent the brand but instead how these brand elements will actually be used in the marketing programme. As the Intel example revealed, it is necessary to go beyond traditional approaches to find creative solutions to increasing the prominence of the brand in marketing strategies. 
Building brand equity, however, involves more than just the choices of brand elements, and strong brands in the twenty-first century will also rise above other brands by better understanding the needs, wants, and desires of consumers to create marketing programmes that fulfil and even surpass consumer expectations. Successful brands will have a rich but internally-cohesive brand image whose associations are highly valued to consumers. Marketing programmes will seamlessly reinforce these associations through product, pricing, distribution strategies, and communication strategies that consistently and creatively inform and remind consumers of what the brand has to offer. Consumers will have a clear picture of what the brand represents and why it is special. Consumers will view these brands as 'old friends' and value their dependability and superiority. Managers of these brands will engage in dialogue with consumers, listening to their product joys and frustrations, and establishing a rapport and relationship that transcends mere commercial exchanges.

\section{MEASURING BRAND EQUITY}

Marketers of successful twenty-first century brands will create formalised measurement approaches and processes that ensure that they continually and exhaustively monitor their sources of brand equity and those of competitors. As part of this process, managers will develop a greater understanding of how different marketing actions affect their sources and outcomes of brand equity. Thus, marketers of successful twenty-first century brands will go beyond piece-meal research projects (eg, periodic advertising campaign evaluations) to devise new and original ways to obtain accurate, comprehensive, and upto-date information on the status of their brands. By maintaining close contact with the brand, managers will be better able to understand just what 'makes their brand tick'. By achieving greater accountability in marketing activities and programmes, it will be possible for managers to better optimise their brand investments, putting money behind the right brands in the right ways at the right time.

\section{MANAGING BRAND EQUITY}

Marketers of successful twenty-first century brands will continually evolve and adapt every aspect of their marketing programmes to enhance brand equity. These marketers will develop a deep understanding of what makes their brand successful, retaining enduring core elements while modifying peripheral elements that fail to add value or unnecessarily absorb costs. Marketers of successful twenty-first century brands will also appreciate how their brands fit in with respect to other brands sold by the firm. They will capitalise on and judiciously exploit the potential of their brand in product development and brand extensions while at the same time recognising its limits and boundaries.

\section{CONCLUSION}

Although the general principles of branding are likely to prevail in the coming years, new approaches to branding will undoubtedly be developed as marketers better understand how to build, measure, and manage brand equity. Innovative marketers will find creative new ways to better design and implement their branding strategies. This editorial has suggested several possible directions along those lines.

\section{Kevin Lane Keller Editorial Board}

\section{Reference}

(1) Much of this editorial is drawn from Keller, K. L. 'Strategic Brand Management', Prentice-Hall, in press. 